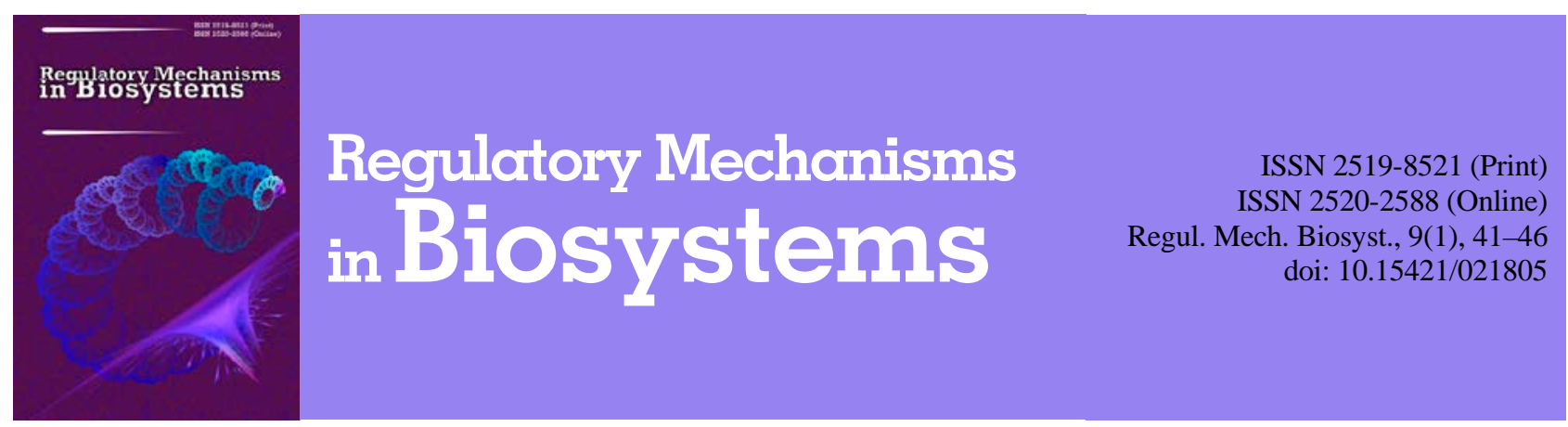

\title{
Hereditary tubulopathies including the associated bone disease
}

\author{
M. O. Ryznychuk, T. V. Khmara, M. I. Kryvchanska, I. I. Zamorskii \\ Higher State Educational Institution of Ukraine "Bukovinian State Medical University”, Chernivtsi, Ukraine
}

Article info

Received 28.12.2017

Received in revised form 26.01.2018

Accepted 29.01.2018

Higher State Educational Institution of Ukraine

"Bukovinian State Medical University", Teatralna Sq., 2, Chernivtsi, 58001, Ukraine. Tel.: +38-050-192-09-53.

E-mail:

rysnichuk.mariana@gmail.com Ryznychuk, M. O., Khmara, T. V., Kryvchanska, M. I., \& Zamorskii, I. I. (2018). Hereditary tubulopathies including
the associated bone disease. Regulatory Mechanisms in Biosystems, 9(1), 41-46. doi: 10.15421/021805

Tubulopathy is a heterogeneous group of diseases combined by the nephron functions disorders of one or more enzyme proteins in the tubular epithelium that cease to function as a reabsorption of one or several substances filtered from the blood through the glomeruli into tubules, which determines the development of the disease. This review addresses the tubulopathies accompanying bone disease, namely: de Tony-Debre-Fanconi syndrome (autosomal dominant, autosomal recessive, X-linked), renal distal metabolic acidosis type I (classic, autosomal dominant, autosomal recessive inheritance), renal distal tubular metabolic acidosis I (autosomal dominant, autosomal recessive inheritance) and type II (autosomal recessive inheritance accompanying delayed mental development and eye disorders), combined distal and proximal renal tubular metabolic acidosis type III (autosomal recessive inheritance characterized by osteoporosis), hypophosphatemia rickets (X-linked dominant, autosomal dominant, primary hypercalciuria, autosomal recessive inheritance). However, the diagnosis of tubulopathy remains complex and requires expensive laboratory equipment and specialist expertise; it can be diagnosed in children showing the following symptoms: impaired growth, vitamin D resistant rickets (lower limb deformities between 2 and 3 years of age). In the evaluation of such patients urine analysis is commonly used (levels of calcium, phosphorus, $\mathrm{pH}$, bicarbonate, sodium, potassium, glucose, creatinine, protein, amino acids), blood count (levels of creatinine, uric acid, alkaline phosphatase, glucose, $\mathrm{pH}$ and sodium, bicarbonate, potassium, chloride, calcium, phosphorus ions), ultrasound of the kidneys to detect nephrocalcinosis. Determination of serum parathyroid hormone concentration, vitamin D metabolites, aldosterone and plasma renin activity, cysteine lymphocyte concentration (suspicion to diagnose cystinosis) and ophthalmologist examination may also be used as additional diagnostic methods. Despite the fact that most tubulopathies can be diagnosed clinically, molecular genetic studies are needed to clarify the type of inheritance and prognosis. The use of calcitriol will help in the management of phosphorous levels in the blood. Correction of vitamin $\mathrm{D}$ deficiency state is not required. Calcitriol supplementation may prevent secondary hyperparathyroidism resulting from increased phosphate intake.

Keywords: vitamin D resistant rickets; children; hypophosphatemia; genes

\section{Introduction}

Tubulopathies form a heterogeneous group of diseases combined by the presence of disorders in the tubular epithelium of the nephron functions of one or more enzyme proteins that cease to function as reabsorption of one or several substances filtered from the blood through the glomeruli into tubules, which determines the development of the disease. By origin they are classified into primary and secondary tubulopathies. The primary ones involve a hereditary defect of the genes that regulate the function of a particular tubular enzyme, resulting in the development of pathology usually from the first months or years of life of the child. Currently, not all genes are known, the mutation of which leads to the development of hereditary tubulopathies.

Based on the etiology, primary tubulopathy is divided into proximal (different forms of Fanconi syndrome, glycineuria, cystonuria, phosphate diabetes, renal tubular acidosis type II (in children), renal glucoseuria, etc.), distal (renal tubular acidosis type I, nephrogenic diabetes insipidus, pseudogiopoaldosteronism) and mixed, and by the number of disturbed functions, such as isolated (monosymptomatic) and combined (polysymptomatic).

For a practical physician a classification based on the isolation of the leading clinical symptom complex is considered optimal. At present, more than 30 different primary tubulopathies are known, their number increases with further study of the pathophysiology of the kidneys. According to some authors, it is advisable to classify tubulopathies according to the leading clinical manifestation. The classification below does not purport to represent all existing hereditary tubulopathies and is limited to the most common diseases.

According to the main syndromes, tubulopathies can be divided into three groups:

1. Tubulopathies accompanying bone diseases (primary de ToniDebre-Fanconi syndrome (autosomal dominant, autosomal recessive, $\mathrm{X}$-linked), renal distal metabolic acidosis type I (classic, autosomal dominant, autosomal recessive inheritance), renal distal tubular metabolic acidosis I (autosomal dominant, autosomal recessive inheritance) and type II (autosomal recessive inheritance accompanied by delayed mental development and eye disorders), combined distal and proximal renal tubular metabolic acidosis type III (autosomal recessive inheritance characterized by osteoporosis), hypophosphatemia rickets (Xlinked dominant, autosomal dominant, primary hypercalciuria, autosomal recessive inheritance).

2. Hereditary tubulopathies accompanying polyuria (renal glycosuria, nephrogenic diabetes insipidus, pseudo hyperaldosteronism).

3. Hereditary tubulopathies characterized by nephrolithiasis (cystinuria, glycosuria, primary hyperoxaluria, xanithinuria, alkapthonuria, Dent disease). 
We provide a brief overview of the tubulopathies associated with bone disease.

\section{Primary de Toni-Debre-Fanconi syndrome (OMIM 134600, 613388, 615605, 616026)}

Syn.: Fanconi syndrome, glucoaminophosphate diabetes, glucosephamide diabetes, rickets hereditary vitamin D-resistant, idiopathic Fanconi syndrome, Fanconi hereditary syndrome, Renal Fanconi syndrome, Fanconi syndrome, Primary de Toni-Debre-Fanconi syndrome, Inherited Fanconi syndrome.

Fanconi syndrome is divided into four types: type I (OMIM 134600), type II (OMIM 613388), type III (OMIM 615605), type IV diabetes with MODY (OMIM 616026).

In its complete form, Fanconi syndrome (disease) is characterized by a triad of symptoms: hypophosphatemia associated with bone disease, excessive renal wasting of glucose and amino acids, arising as a result of violations in the proximal segment of the nephron (Bacconi et al., 2005).

Is associated with the most severe types of prolapsed tubulopathies. The disease is genetically predisposed (Bai et al., 2004; White et al., 2005).

Among other researchers, a Swiss pediatrician Fanconi was the first to describe the particular signs of the disease. In 1931, he described a child with dwarfism, rickets, glycosuria and albuminuria. Two years later, de Toni found hypophosphatemia to be further clinical evidence and, later on, Debré determined elevated levels of organic acids in urine, called aminoaciduria (Younes et al., 2003; Zivičnjak et al., 2011).

Aetiopathogenesis

It is believed that the genetically determined defects of enzymatic phosphorylation in the renal tubules (combined tubulopathy); deficiency of enzymes from the complexes II and III (succinate dehydrogenase and cytochrome oxidase) of the respiratory chain are the basis of the disease. Some authors believe that the basis of the disease is mitochondrial genesis (Lichter-Konecki et al., 2001; Watanabe, 2017).

These mutations lead to various defects in the renal proximal tubules leading to excessive urinary waste of phosphates, glucose and amino acids, as well as to the acid-base imbalance. Metabolic acidosis and insufficiency of phosphorus compounds can also contribute to bone deformities (osteomalacia (adults) and rickets (children)) (Pishak et al., 2015).

Based on its etiology, the syndrome can be divided into two main categories: primary (hereditary) and secondary (acquired). The seconddary one is the most common.

The primary (hereditary) syndrome resulting from a genetic mutation occurs in approximately 1 in 20.000 births, de Tony-Debre-Fanconi disease occurs in approximately 1 in 40.000 births. This disease is believed to be caused by the damage to the transport systems in the proximal tubules resulting in disruption of phosphate, glucose and amino acids transportation. Typical episodic features include dehydration, symptoms of rickets and delayed growth. Sometimes the disorder manifests itself at an older age as a renal failure (Tasic, 2008; Besouw et al., 2017). Damage to the sodium transport systems in the proximal tubules (for example, in acute renal failure) leads to a pronounced sodium reabsorption and tubular acidosis disorder, hydrogen ion transport and proximal tubules reabsorbed substances can be disrupted: glucose, phosphate, uric acid, amino acids.

An acquired Fanconi syndrome develops associated with other hereditary disorders or kidney diseases, namely: congenital metabolism or transport disorders (cystitis, tyrosineemia type I, glycogenosis type $\mathrm{XI}$, galactosemia, congenital intolerance to fructose, Wilson disease, oculocerebrorenal syndrome (Lowe syndrome), vitamin D-resistant rickets, impaired energy metabolism, McArdle-Schmid-Pearson disease, cytochrome $\mathrm{C}$ oxidase deficiency (COX deficiency), pyruvate carboxylase (PC) deficiency, carnitine palmitoyltransferase I (CPT I) deficiency); chronic diseases (paraproteinemia (multiple myeloma), tubulointestitial nephropathies, nephrotic syndrome, nephropathy in renal transplant allografts, malignant tumors (paraneoplastic disease)); heavy metal salts intoxication (mercury, lead, cadmium, uranium); organophosphate poisoning (toluene, maleic acid, lysol); drug-induced toxicity (platinum-based agents, expired tetracycline and gentamicin), severe burns. The syndrome may be complete if these three symptoms (glycosuria, phosphaturia and aminoaciduria) are observed and incomplete if there are only two of them:

- glycosophosphamide diabetes without acidosis (described by Dent and Kyle);

- phosphoglucide diabetes (described by Mac Cune);

-aminophosphoric diabetes (describedby Jonxin, Wallgren and Nicola);

- glucosamine diabetes (described by Juillard and Fischer).

Clinical evidence

The severity of clinical manifestations and metabolic disorders may differ depending on two clinical and biochemical variants of the disease: in children (early) and adults (late). The pediatric form arises during the 1 st year of life and manifestations can include frequent vomiting, loss of appetite, mental and physical developmental delay, a tendency to severe infectious diseases. Gradually there is a proportional dwarfism, rickets and renal insufficiency.

Early dwarfism: intense increase in the rate of growth in height and weight (up to 30\%) that occurs during the 5-6 of normal growth and weight gain.

Median age at diagnosis of rickets is 10-12 months; it is characterized by a topographical specificity: the skull is deformed by localized impact; in contrast to fractures in the thoracic (mid back) spine and limbs. Bone pain of moderate intensity primarily tends to be localized in the limbs and spine. It is associated with severe hypocalcaemia (1.6$1.8 \mathrm{mmol} / \mathrm{L}$ ) and reduced intestinal calcium absorption.

Polydipsia and polyuria are common for the beginning of the disease, progressively intensifying and systematically regressing at different age periods, but never go away completely.

General symptoms of chronic inflammatory myopathy include slow but progressive muscle weakness and transverse abdominal disruption. It is marked by frequent constipation.

Eye disorders: pigment retinitis, congenital cataracts. Renal failure progresses into a chronic kidney disease between 8-14 years.

The late syndrome is generally noticed between 3 and 6 years of age; it is accompanied by the delayed changes in general medical condition, osteomalacia augmentation and hypokalemic paralysis. Characterized by polyuria and polydipsia, moderate developmental delay, severe genu valgum deformities; low level of phosphate, potassium and calcium in the blood, normal amino acids and glucose concentration. Low plasma bicarbonate concentration is common in the early stages of the disease, later on hyperchloremic acidosis develops. It is characterized by disturbances in the concentration of renal function (hipostenuria, polyuria), sometimes moderate proteinuria, generalized hyperaminociduria, elevated excretion of phosphates, calcium, glucose, citrates in patients. Urine reaction is neutral or alkaline (Lichter-Konecki et al., 2001; Tasic et al., 2008; Watanabe, 2017).

In patients with de Toni-Debre-Fanconi syndrome the following laboratory abnormalities:

- hypophosphatemia;

- hypocalcemia;

- hypokalemia;

- hyponatremia;

- elevated alkaline serum phosphatase;

- metabolic acidosis (pH: 7.25-7.35; base excess BE (elevated level of alkalinity): $-12--10 \mathrm{mmol} / \mathrm{L}$ ) secondary to reduced proximal tubular reabsorption of bicarbonate:

- increased Pyruvic and Lactic Acid Content of Blood;

- hypophosphaturia;

- calciuria;

- polyuria;

- decreased serum uric acid with an increased uric acid clearance;

- glycosuria (above 20-30 g/L);

- development of generalized hyperaminociduria (less than 2.0

$2.5 \mathrm{~g} / 24 \mathrm{~h}$ ) in all the amino acid types;

- failure of amino acid genesis - reduce titratable acidity;

- increased urine $\mathrm{pH}$ (higher than 6.0);

- tubulin-like proteinuria - the presence of immunoglobulins in the urine of the light chains, lysozyme, $\beta_{2}$-microglobulin.

Radiological method features has proven to be useful in detecting pronounced osteoporosis with severe disorders in metaphyseal areas 
with characteristic bowing of the bones, accompanied by a delayed bone age relative to chronological age of a child.

Additionally, type II is characterized by increased serum 25-hydroxyvitamin D levels in children and decreased - in adults (Levtchenko et al., 2006; Magen et al., 2010). In type III, varus angulation of the lower extremities, while renal failure does not occur (Klootwijk et al., 2014). Type IV could be suspected in infants who are large for their gestational age (more than $4 \mathrm{~kg}$ ), subject to neonatal hypoglycemia, hyperinsulinism and hepatomegaly. There is a risk of development of insulin dependent diabetes mellitus (maturity-onset diabetes of the young (MODY)) accompanied by nephrocalcinosis and renal failure (Hamilton et al., 2014).

Treatment

Dietary restrictions:

- in galactosemia: milk;

- in fructose intolerance: sugar, honey, apples, pears, watermelons, carrots;

- in cystonesis: protein foods, high-methionine foods, kitchen salt;

- in tyrosinemia: high-tyrosine and methionine foods;

Recommended foods (Novikov et al., 2004; Savenkova and Leviashvili, 2004):

-inpynuvatecarboxylase deficiency: low carb high fat diet (LCHF diet);

- potassium-, calcium-, phosphorus-rich foods;

- liquid intake is typically not restricted.

Correction for renal tubular metabolic acidosis:

- $2 \%$ or $4 \%$ sodium bicarbonate solution ( $5 \mathrm{ml} / \mathrm{kg} / \mathrm{day}$ ) in 4 divided

doses (intravenous, oral, rectal administration) and calcium supplements;

- citrate mixture to reduce the dose of sodium bicarbonate;

- treatment of hypokalaemia (potassium supplements);

Correction for hypophosphatemic rickets with normal calcium level and/or hypocalcemia, osteoporosis:

- calcium supplements (calcium carbonate, calcium phosphate, calcium citrate, calcium glycerophosphate). Phosphate buffer (continuously);

Active metabolites of vitamin D: oxide; calcidiol; calcitriol; or calcium-, phosphorus- and calcitriol- containing binding agents.

Recombinant human growth hormone treated with $0.6-0.7 \mathrm{IU} / \mathrm{kg} /$ week of rhGH administered daily for 3 months.

\section{Renal tubular acidosis (RTA)}

Several bone deformities in children with tubulopathies are associated with a number of factors; metabolic acidosis should be considered a sign of an underlying disease process. The most vital parameter affecting protein binding of calcium is the $\mathrm{pH}$. Since bone responds to overacidity, chronic metabolic acidosis of any origin can cause growth retardation. In addition, metabolic acidosis causes alterations in the bone reabsorptive capacity for calcium and therefore increases urinary calcium excretion. The development of metabolic acidosis is caused by a violation of reabsorption of bicarbonates and secretion of hydrogen ions, as well as a violation of the activity of carbonic anhydrase with respect to hydration of $\mathrm{CO}_{2}$ (this enzyme also stimulates proton secretion not only in renal proximal tubules and collecting ducts, but also in osteoclasts) (Kartamyisheva et al., 2011).

The disease is inherited by both auto dominant and auto recurrent types; and is clinically characterized by hyperchloremic acidosis and baseline deficiency in the serum.

There are two types of disease: distal renal tubular acidosis (dRTA) type I is characterized by an impairment of the normal urinary acidifycation process in the distal part of the nephron; Proximal renal tubular acidosis (pRTA) type II is characterized by a defect in the ability to reabsorb bicarbonates in the proximal tubule. Type III is a combination of isolated proximal (type 2) or distal (type 1) tubular pathologies.

Type I dRTA

There are distinguished two types of the disease by the pattern of inheritance: autosomal dominant or autosomal recessive.

Classical type I dRTA autosomal dominant (OMIM 179800)

The syndrome is caused by mutations in the SLC4A1 (MIM 109270) gene, found in a place on the long arm of chromosome 17 called 17q21.31 (Bergwitz et al., 2006). Clinically it is characterized by osteomalacia, plastic deformity of the long tubular bones and growth retardation. It is caused by the disorder of the tubular acidogenesis, when the kidneys fail to reduce the urine $\mathrm{pH}$ associated with the increase in hydrogen ion concentration as a result of the increased reverse diffusion of hydrogen ions through the tight junctions that hold the tubular epithelial cells. The distal canal is unable to create a concentration gradient between the tubular fluid and the blood. This finding suggests that bicarbonate ions have been effectively replaced by chloride ions and the hyperchloremic metabolic acidosis arises (Fry \& Karet, 2007; Kraut et al., 2010).

First, in people with this syndrome in their teens or adulthood the following signs and symptoms are observed : poor appetite, polyuria, polydipsia, rapid fatigability and delayed physical development. Next bone deformities commonly associated with rickets (lower-limb valgus deformity, "rachitic rosary", widening of wrist, frontal and parietal lobe), as well as with the pronounced muscular hypotonia. The first manifestations of the renal tubular acidosis usually appear in children two years of age. People with more severe and prolonged rickets may experience permanent bone deformities (Rodriguez, 2002; Karet, 2002; Civitelli \& Ziambaras, 2011).

Laboratory studies have revealed metabolic acidosis, low plasma bicarbonate- and increased plasma chloride concentration, hypocalcemia, hypokalemia, hypophosphatemia, increased alkaline phosphatase activity, secondary hyperparathyroidism and decreased intestinal calcium absorption. High-resolution ultrasound has been found to be a sensitive and reliable method for the detection of nephrocalcinosis. A significantly decreased renal function (urine specific gravity from 1001 to1008) is observed, a persistently low urine $\mathrm{pH}(<5.5)$, as well as normal bicarbonate levels. Hypercalciuria is associated with excessive urinary calcium excretion (as a compensation for a metabolic acidosis) (Bergwitz \& Jüppner, 2010; Escobar et al., 2013) mediated by the renal $\mathrm{Ca}^{2+}$ transport proteins (Laing \& Unwin, 2006; Nijenhuis et al., 2006) and increased renal sodium reabsorption. This association may implicate increased renal blood flow as a contributory cause of urinary hyperexcretion of insoluble mineral salts, which can lead to recurrent kidney stones or nephrocalcinosis. These factors, together with high urine $\mathrm{pH}$, contribute to abnormal accumulation of calcium and the development of nephrocalcinosis and / or renal stones, which may lead to further deterioration of renal function (Karet, 2002; Loymana et al., 2010).

Type I autosomal recessive dRTA with deafness or with preserved hearing (OMIM 602722) Syn.: RTADR.

Defects in the ATP6V0A4 (7q34) or ATP6V1B1 (2p13.3) genes cause autosomal recessive dRTA with deafness and with preserved hearing, respectively. However, several patients with ATP6V0A4 mutations have developed hearing loss, usually in young adulthood.

Clinical features. This syndrome occurs in early childhood associated with frequent vomiting and development of dehydration followed by growth retardation and nephrocalcinosis, preceded by chronic renal insufficiency. Often the syndrome is associated with the development of neurosensory deafness. Laboratory findings are the same as in the autosomal dominant form. Parents are usually married (Leung, 2014).

Type II proximal renal tubular acidosis with ocular abnormalities and mental retardation (OMIM 604278)

The syndrome is caused by the function mutations in the SLC4A4 gene (MIM 603345) located on chromosome 4 (4q13.3) (Igarashi et al., 2001).

It is associated with the immature nephrons, low carbonic anhydrase II(c) and I(b) activity; as well as low HCO3- ATPase activity in mitochondria of renal tubular cells.

Clinical features. Reduced proximal tubular reabsorption of bicarbonate, resulting in impaired capacity for net acid excretion and persistent hyperchloremic metabolic acidosis. In the first few months of life a history of vomiting, thirst, subfebrile temperature, marked delay in physical growth, rickets-like changes in the skeleton may be present. Developmental delay, nystagmus, congenital cataracts, corneal stromal opacities, glaucoma and permanent enamel hypoplasia (Pettifor, 2008).

Laboratory diagnosis: increased osmotic fragility of erythrocytes with slightly acid urine ( $\mathrm{pH}$ less than 6). Hydrogen ions $\left(\mathrm{H}^{+}\right)$excretion remains within normal limits and corresponds to nutrition. The bicarbonate threshold for bicarbonate reabsorption is decreased, while its excretion is sharply increased. 
Treatment: Dietary restriction of oxalate intake (sorrel, spinach, tomato juice, chocolate, etc.), alkaline mineral water, administration of sodium bicarbonate to restore normal acid base status; or diluted citrate solution (Shohla solution) at a dose $5-30 \mathrm{mmol} \mathrm{HCO}_{3}^{-} / \mathrm{kg} /$ day. Adding more potassium is typically needed. Shohla solution (pharmacy - prepared) containing in $1000 \mathrm{~mL}$ not less than $140 \mathrm{~g}$ of citric acid and $90 \mathrm{~g}$ of sodium citrate $\left(1 \mathrm{~g}\right.$ of $\mathrm{NaHCO}_{3}=12 \mathrm{mg}$ of alkalosis, $10 \mathrm{ml}$ of Shohla solution $=10 \mathrm{mg}$ of alkalosis). Vitamin D treatment in patients with osteoporosis and osteomalacia.

Combined proximal and distal renal tubular acidosis (Type III RTA) (Autosomal recessive inheritance associated with osteoporosis) (OMIM 267200)

The syndrome is almost invariably associated with increased bicarbonate excretion.

Clinical features. Metabolic acidosis in early infancy associated with hypokalemic paralysis, osteomalacia with subsequent skeletal deformities and growth retardation and early osteoporosis.

Radiographic evaluation of nephrocalcinosis, abdominal calcifications, osteoporosis and bone deformation. Autosomal recessive inheritance, much more prevalent in males.

\section{Hypophosphatemic rickets (hypophosphatemia)}

The maintenance of normal phosphate homeostasis constitutes the basic physiologic function of the kidneys (Bastepe \& Jüpper, 2008; Natochin, 2008). Serum phosphate concentration exists in three major forms: free ionized (84-85\%), protein-bound (10\%), and calcium-, magnesium- and sodium compounds (1\%) (Escobar et al., 2013). If urine $\mathrm{pH}$ is $>7.4$, approximately $80 \%$ of total phosphate concentration is in the divalent form $\left(\mathrm{HPO}_{4}{ }^{2-}\right)$, while $20 \%$ will be in the monovalent form $\left(\mathrm{H}_{2} \mathrm{PO}^{2-}\right)$ (Kartamyisheva et al., 2011). Usually, about $90 \%$ of phosphate in the glomerular filtrate is reabsorbed in the proximal tubule, and 80\% reabsorbed proximally (Bastepe \& Jüpper 2008; Natochin, 2008; Escobar et al., 2013). The currently known main regulators of phosphate homeostasis include parathyroid hormone (PTH) and vitamin $\mathrm{D}_{3}$ (calcitriol) (Escobar et al., 2013) and leads to a higher plasma phosphorus concentration (Baroncelli et al., 2012).

Calcitriol or biologically active form of vitamin $\mathrm{D}_{3}$ stimulates phosphate reabsorption. Phosphatonins include fibroblast growth factor 23, frizzled-related protein-4 and phosphoglycoprotein extracellular matrix. Fibroblast growth factor-23 (FGF-23) is a 26-kDa protein activating the specific cell surface receptors(FGFRs) (Perwad \& Portale, 2011).

The ENPP1 (173335), PHEX (300550), DMP1 (600980) and FGF23 genes stimulate the elevation of fibroblast growth factor 23 (FGF-23). The FGF-23 gene is located on chromosome 12p13.3. Fibroblast growth factor 23 (FGF-23) is the gene identified as causative for autosomal dominant hypophosphatemia rickets (Bai et al., 2004; Ben-Dov et al., 2007).

The biological activity and physiological role of FGF-23 have recently been clarified. Several animal models (mice with excess FGF-23 activity as a result of in vivo forced overexpression) exhibit hypophosphatemia and increased P excretion of 1.25-dihydroxyvitamin D (Sitara et al., 2004, Shimada et al., 2004a; Shimada et al., 2004b). FGF-23 deficient mice are characterized by a severe aging-like phenotype associated with ectopic calcifications organ atrophy, and osteomalacia. Mice lacking FGF-23 were characterized by severe vascular- and soft tissue calcification (Kuro-o et al., 1997). Needless to mention that extensive vascular and soft tissue calcification in both FGF-23 and klotho ablated mice are associated with severe hyperphosphatemia, and increased serum level of hydroxyvitamin D. The FGF-23 biology was studied on mouse models treated with recombinant FGF-23 or overexpression of FGF-23. FGF-23 suppresses the expression of the types IIa and IIc sodium-phosphate cotransporters on the apical membrane of renal proximal tubular cells, thus inducing phosphaturia (Shimada et al., 2005). The phosphatidic action of FGF-23 is not expressed in the absence of sodium-hydrogen exchanger regulatory factor-1 (NHERF-1) and increases in the presence of parathyroid hormone (PTH). In addition, FGF-23 suppresses the formation of 1,25(OH $)_{2} \mathrm{D}$, suppressing 1-alpha-hydroxylase (CYP27B1), which converts 25-hydroxyvitamin $\mathrm{D}[25(\mathrm{OH}) \mathrm{D}]$ to $1,25(\mathrm{OH}) 2 \mathrm{D}$ and stimulates the formation 24-hydroxylase (CYP24), which converts $1,25(\mathrm{OH})_{2} \mathrm{D}$ into inactive metabolites in the proximal tubule of the kidneys. In addition, FGF-23 impairs the production of renal 1,25-dihydroxyvitamin $\mathrm{D}\left[1,25(\mathrm{OH})_{2} \mathrm{D}\right]$ by inhibiting the expression of CYP27B1, the enzyme that converts $25-(\mathrm{OH}) \mathrm{D}$ to inactive metabolites in the proximal tubule. FGF23 also reduces the expression of interstitial sodium-phosphate conveyor NPT2b (Saito et al., 2003), reducing the intestinal phosphate absorption.

FGF-23 acts directly on the parathyroid gland to inhibit PTH synthesis and secretion. It has been shown that FGF-23 activates the mitogen-activated protein kinase pathway leading to a decrease in parathyroid hormone (PTH) secretion both in vivo rats and in vitro shingles (Ben-Dov et al., 2007). FGF-23 has also been shown to increase expression of parathyroid 1-alpha-hydroxylase (Krajisnik et al., 2007), which converts 25 -hydroxyvitamin $\mathrm{D}[25(\mathrm{OH}) \mathrm{D}]$ to $1,25(\mathrm{OH})_{2} \mathrm{D}$.

FGF-23 secretion is regulated by local bone-derived factors, such as phosphate-regulating gene with homologies to endopeptidases and dentin matrix protein-1 (Lorenz-Depiereux et al., 2006a; Lorenz-Depiereux et al., 2006b). 1,25(OH) $)_{2} \mathrm{D}$ affects FGF-23 secretion both in vivo and in vitro through the activation of FGF-23 mediated vitamin D (Liu et al., 2006).

1. Factors decreasing phosphate reabsorption:

- parathyroid hormone;

- atrial natriuretic peptide;

- glucocorticoids;

- dopamine.

Phosphauric factors:

- fibroblasts 23 growth factor;

- fibroblasts 7 growth factor;

- matrix extracellular phosphoglycoprotein (MEPE);

- other.

2. Factors increasing phosphate reabsorption:

- parathyroidectomy;

$-11 \alpha 25(\mathrm{OH})_{2} \mathrm{D}_{3}$

- growth hormone;

- insulin-like growth factor;

- food regulation;

- acute (minutes, hours);

- chronic (hours, days);

- several system factors.

$X$-linked recessive hypophosphatemia rickets (Dent's disease) (OMIM 300554)

The disease is caused mainly by mutations in the CLCN5 gene located on chromosome Xp11.22.

$\mathrm{X}$-linked recessive hypophosphatemia rickets is a form of $\mathrm{X}$-linked hypercalciuric nephrolithiasis, which comprises a group of disorders characterized by proximal renal tubular reabsorptive failure, hypercalciuria, nephrocalcinosis, and renal insufficiency.

Clinical features: rickets or osteomalacia, hypercalciuria, hypophosphatemia and proteinuria in children. Progressive calcification and renal failure in adult patients (Gambaro et al., 2004). Clinically, it may show bone pain, fatigue, muscle weakness, and repeated bone fractures. Symptoms are related to bone pain, fatigue, muscle weakness and recurrent bone fractures.

Autosomal dominant hypophosphatemia rickets (OMIM 193100)

Autosomal dominant hypophosphatemia rickets (ADHR) results from activating mutations in a fibroblast growth factor 23 (FGF-23) gene in chromosome 12p13 encoding a phosphate-regulating hormone (Sun et al., 2012; Wöhrle et al., 2013).

Small amounts of the gene originate in the brain, thymus, small intestine, heart, liver, lymph nodes, thyroid-shaped and pterygoid glands, bone marrow and in large quantities in tumors with oncogenic osteomalacia. No expression in the bones. Elevated levels of FGF-23 are associated with inhibition of reabsorption of phosphates in the renal tubule and hypophosphatemia. FGF-23 can physiologically function as a locally active factor secreted in excessive amounts in conditions of pathology, and may cause renal phosphate loss.

Less than 100 cases have been described.

Clinical manifestations depend on the age of onset and on the severity of hypophosphatemia. 
Clinical features: ADHR shows incomplete penetrance and variable age at onset (childhood to adult). Phosphate excretion can be evaluated by measuring the maximum tubular reabsorption per glomerular filtration rate.

Laboratory diagnosis: It is characterized by severe hypophosphatemia arising from a defect in the renal reabsorption of filtered inorganic phosphorus $\left(\mathrm{P}_{\mathrm{i}}\right)$, elevated serum alkaline phosphatase activity and fibroblast growth factor 23 (FGF-23), inappropriately low-normal serum concentration of 1,25-dihydroxyvitamin D3 [1,25(OH)2D3] levels for the degree of prevailing hypophosphatemia (Econs et al., 1997).

Treatment: aimed at improving growth, enhancing mineralization of bones, and preventing skeletal deformities caused by rickets. It consists of daily oral administration of phosphate and calcitriol and is associated with frequent monitoring of calcium, alkaline phosphatase and parathyroid hormone, and phosphate serum concentrations, as well as urinary calcium and creatinine.

Autosomal recessive hypophosphatemia rickets type 1 (ARHR1) (OMIM 241520)

ARHR1 is caused by homozygous loss-of-function mutations in the DMP1 (Dentin matrix protein 1) gene in chromosome 4q22.

Clinical features: Lower-extremity deformities. No response to vitamin D therapy (vitamin D resistant rickets), high bone density. Back pain, restricted joint motion. Premature fusion of the skull bones. Deafness (aplasia of the vestibulocochlear nerve that results in ipsilateral congenital sensorineural hearing loss). Dental defects and early caries. It is accompanied by muscle weakness and pathologic fractures.

Radiographic evaluation: early osteosclerosis and skull thickening, trabecular bone density in ribs (Feng et al., 2006; Lorenz-Depiereux et al., 2006a).

Laboratory diagnosis: there are no symptoms of hypophosphatemia.

Autosomal recessive hypophosphatemia rickets type 2 (ARHR2) (OMIM 613312)

ARHR2 is caused by homozygous loss-of-function mutation in the ENPP1 gene in chromosome 6 (6q). Mutations in ENPP1 gene are also responsible for generalized arterial calcification of infancy.

Clinical features: hypophosphatemia rickets, sometimes generalized arterial calcification of infancy (Lorenz-Depiereux et al., 2010).

Laboratory diagnosis: hypophosphatemia.

$X$-linked, dominant, hypophosphatemia rickets (XLHR) (OMIM 307800)

Inactivating mutations in PHEX gene with homologies to endopeptidase on the $\mathrm{X}$ chromosome (Xp22) have been identified as a cause of XLHR. This endopeptidase is mainly expressed in bones and teeth, regulating FGF-23 synthesis. The disease occurs as an X-linked dominant disorder with complete penetrance often complicated by variable expressivity.

PHEX revealed possible alternative regulatory mechanisms for phosphate homeostasis, bone mineralization, and vitamin D metabolism. It controls sodium-dependent phosphate transport proteins in intestinal and renal proximal tubular epithelial cells. The genetic disorder is associated with inability of the renal proximal tubule to reabsorb phosphate, which affects intestinal phosphate absorption. PHEX is primarily expressed in osteoblasts, odontoblasts, lung, ovary, parathyroid gland, brain and muscle. We found no correlation between the location or type of mutation and the disease severity.

In XLHR osteoblast is likely to produce some inhibitor. Moreover, it was reported that cross-transplantation of kidneys in hyp-children results in transfer of the mutant phenotype. It can be associated with the primary defect in osteoblasts, as the correction of hyperphosphatemia and calcitriol in patients were observed low mineralization zones around osteolytic lacunae. XLH is the most frequent form of hypophosphatemia rickets, with a prevalence of $1 / 20.000$. The disease affects both sexes. Patients with early onset disease have phosphate wasting, rickets, and lower extremity deformities in childhood.

Characteristics heritable dental developmental anomalies: enamel hypoplasia, dentinogenesis imperfecta, enlarged dentinal tubules, leading to tooth abscess. Characteristic cranial base abnormalities: thickening of outer cortical table of frontal bone and slightly sunken median line between the eyes at the forehead. Osteoarthritis of the lower extremities is developed in adults, osteophytes are formed and in some cases hearing loss may occur. Muscular weakness and hypotension are not observed. Other clinical manifestations, such as enthesopathy (calcifycation of ligaments and their attachment to bone), which is accompanied by joint pain and joint mobility disorders (Baroncelli et al., 2012).

Laboratory diagnosis: hypophosphatemia with low renal phosphate reabsorption, normal serum calcium values, normal or low vitamin $\mathrm{D}$ serum level $\left(1,25(\mathrm{OH})_{2} \mathrm{D}_{3}\right.$ or calcitriol), normal serum parathyroid hormone levels and increased serum alkaline phosphatase activity.

Therapy aimed at normalization of PHT levels with calcitrol supplementation and calcitriol. Correction of vitamin D deficiency state is not required. Calcitriol supplementation may prevent secondary hyperparathyroidism resulting from increased phosphate intake (Gaucher et al., 2009).

\section{Conclusions}

Although the diagnosis of tubulopathy remains complex and requires expensive laboratory equipment and specialist expertise; it can be diagnosed in children showing the following symptoms: impaired growth, vitamin $\mathrm{D}$ resistant rickets (lower limb deformities between 2 and 3 years of age). In the evaluation of such patients urine analysis is commonly used (levels of calcium, phosphorus, $\mathrm{pH}$, bicarbonate, sodium, potassium, glucose, creatinine, protein, amino acids), blood count (levels of creatinine, uric acid, alkaline phosphatase, glucose, $\mathrm{pH}$ and sodium, bicarbonate, potassium, chloride, calcium, phosphorus ions) and ultrasound of the kidneys to detect nephrocalcinosis. Determination of serum parathyroid hormone concentration, vitamin D metabolites, aldosterone and plasma renin activity, cysteine lymphocyte concentration (suspicion to diagnose cystinosis) and ophthalmologist examination may also be used as additional diagnostic methods. Despite the fact that most tubulopathies can be diagnosed clinically, molecular genetic studies are needed to clarify the type of inheritance and prognosis.

\section{References}

Bacconi, A., Virkki, L. V., Biber, J., Murer, H., \& Forster, L. C. (2005). Renouncing electroneutrality is not free of charge: Switching on electroogenicity in a $\mathrm{Na}^{+}$-coupled phosphate cotransporter. Proceedings of the National Academy of Sciences of the USA, 102(35), 12606-12611.

Bai, X., Miao, D., Li, J., Goltzman, D., \& Karaplis, A. C. (2004). Transgenic mice overexpressing human fibroblast growth factor 23 (R176Q) delineate a putative role for parathyroid hormone in renal phosphate wasting disorders. Endocrinology, 145(11), 5269-5279.

Baroncelli, G. I., Toschi, B., \& Bertelloni, S. (2012). Hypophosphatemic rickets. Current Opinion in Endocrinology, Diabetes and Obesity, 19(6), 460-467.

Bastepe, M., \& Jüpper, H. (2008). Inherited hypophosphatemic disorders in children and the evolving mechanisms of phosphate regulation. Reviews in Endocrine and Metabolic Disorders, 9(2), 171-180.

Ben-Dov, I. Z., Galitzer, H., Lavi-Moshayoff, V., Goetz, R., Kuro-o, M., Mohammadi, M., Sirkis, R., Naveh-Many, T., \& Silver, J. (2007). The parathyroid is a target organ for FGF23 in rats. The Joumal of Clinical Investigation, 117(12), 4003-4008.

Bergwitz, C., \& Jüppner, H. (2010). Regulation of phosphate homeostasis by PTH, vitamin D, and FGF23. Annual Review of Medicine, 61, 91-104.

Bergwitz, C., Roslin, N., Tieder, M., Loredo-Osti, J. C., Bastepe, M., Abu-Zahra, H., Frappier, D., Burkett, K., Carpenter, T. O., Anderson, D., Garabedian, M., Sermet, I., Fujiwara, T. M., Morgan, K., Tenenhouse, H. S., \& Juppner, H. (2006). SLC 34A3 mutations in patients with hereditary hypophosphatemic rickets with hypercalciuria predict a key role for the sodiummphosphate cotransporter $\mathrm{NaP}(\mathrm{i})$ in maintaining phosphate homeostasis. The American Journal of Human Genetics, 78(2), 179-192.

Besouw, M. T. P., Bienias, M., Walsh, P., Kleta, R., Van’t Hoff, W. G., Ashton, E., Jenkins, L., \& Bockenhauer, D. (2017). Clinical and molecular aspects of distal renal tubular acidosis in children. Pediatric Nephrology, 32(6), 987-996.

Civitelli, R., \& Ziambaras, K. (2011). Calcium and phosphate homeostasis: Concerted interplay of new regulators. Journal of Endocrinological Investigation, 34(7 Suppl), 3-7.

Escobar, L., Mejia, N., Gil, H., \& Santos, F. (2013). Distal renal tubular acidosis: A hereditary disease with an inadequate urinary $\mathrm{H}^{+}$) excretion. Nefrologia, 33(3), 289-296.

Feng, J. Q., Ward, L. M., Liu, S., Lu, Y., Xie, Y., Yuan, B., Yu, X., Rauch, F., Davis, S. I., Zhang, S., Rios, H., Drezner, M. K., Quarles, L. D., Bonewald, L. F., \& White, K. E. (2006). Loss of DMP1 causes rickets and osteomalacia 
and identifies a role for osteocytes in mineral metabolism. Nature Genetics, 38(11), 1310-1315.

Fry, A. C., \& Karet, F. E. (2007). Inherited renal acidoses. Physiology (Bethesda), 22, 202-211.

Gahl, W. A., Thoene, J. G., \& Schneider, J. A. (2002). Cystinosis. The New England Journal of Medicine, 347(2), 111-121.

Gambaro, G., Vezzoli, G., Casari, G., Rampoldi, L., D’Angelo, A., \& Borghi, L. (2004). Genetics of hypercalciuria and calcium nephrolithiasis: From the rare monogenic to the common polygenic forms. American Journal of Kidney Diseases, 44(6), 963-986.

Gaucher, C., Walrant-Debray, O., Nguyen, T. M., Esterle, L., Garabédian, M., \& Jehan, F. (2009). PHEX analysis in 118 pedigrees reveals new genetic clues in hypophosphatemic rickets. Human Genetics, 125(4), 401-411.

Hamilton, A. J., Bingham, C., McDonald, T. J., Cook, P. R. Caswell, R. C., Weedon, M. N., Oram, R. A., Shields, B. M., Shepherd, M., Inward, C. D., Hamilton-Shield, J. P., Kohlhase, J., Ellard, S., \& Hattersley, A. T. (2014). The HNF4A R76W mutation causes atypical dominant Fanconi syndrome in addition to a beta cell phenotype. Journal of Medical Genetics, 51(3), 165-169.

Karet, F. E. (2002). Inherited distal renal tubular acidosis. Joumal of the American Society of Nephrology, 13(8), 2178-2184.

Kartamyisheva, N. N., Vashurina, T. V., Mazo, A. M., Sugak, A. B., Tsyigina, E. N., Bakanov, M. I., \& Tsyigin, A. N. (2011). Kanaltsevyie disfunktsii s rahitopodobnyim sindromom [Tubular dysfunction with rickets-like syndrome]. Pediatricheskaya Farmakologiya, 8(4), 140-145 (in Russian).

Klootwijk, E. D., Reichold, M., Helip-Wooley, A., Tolaymat, A., Broeker, C., Robinette, S. L., Reinders, J., Peindl, D., Renner, K., Eberhart, K., Assmann, N., \& Oefner, P. J. (2014). Mistargeting of peroxisomal EHHADH and inherited renal Fanconi's syndrome. The New England Journal of Medicine, 370(2), 129-138.

Krajisnik, T., Björklund, P., Marsell, R., Ljunggren, O., Akerström, G., Jonsson, K. B., Westin, G., \& Larsson, T. E. (2007). Fibroblast growth factor-23 regulates parathyroid hormone and 1 alpha-hydroxylase expression in cultured bovine parathyroid cells. Journal of Endocrinology, 195(1), 125-131.

Kraut, J. A., \& Madias, N. E. (2010). Metabolic acidosis: Pathophysiology, diagnosis and management. Nature Reviews Nephrology, 6(5), 274-285.

Kuro-o, M., Matsumura, Y., Aizawa, H., Kawaguchi, H., Suga, T., Utsugi, T., Ohyama, Y., Kurabayashi, M., Kaname, T., Kume, E., Iwasaki, H., Iida, A., Shiraki-Iida, T., Nishikawa, S., Nagai, R., \& Nabeshima, Y. I. (1997). Mutation of the mouse klotho gene leads to a syndrome resembling ageing. Nature, 390(6655), 45-51.

Laing, C. M., \& Unwin, R. J. (2006). Renal tubular acidosis. Journal of Nephrology, Suppl. 9, 546-552.

Leung, J. C. (2014). Inherited renal diseases. Current Pediatric Reviews, 10(2), 95-100.

Levtchenko, E. N., van Dael, C. M., de Graaf-Hess, A. C., Wilmer, M. J., van den Heuvel, L. P., Monnens, L. A., \& Blom, H. J. (2006). Strict cysteamine dose regimen is required to prevent nocturnal cystine accumulation in cystinosis. Pediatric Nephrology, 21(1), 110-113.

Lichter-Konecki, U., Broman, K. W., Blau, E. B., \& Konecki, D. S. (2001). Genetic and physical mapping of the locus for autosomal dominant renal Fanconi syndrome, on chromosome 15q15.3. The American Journal of Human Genetics, 68(1), 264-268.

Liu, S., Tang, W., Zhou, J., Stubbs, J. R., Luo, Q. P. M., \& Quarles, L. D. (2006). Fibroblast growth factor 23 is a counter-regulatory phosphaturic hormone for vitamin D. Journal of the American Society of Nephrology, 17(5), 1305-1315.

Lorenz-Depiereux, B., Bastepe, M., Benet-Pages, A., Amyere, M., Wagenstaller, J., Muller-Barth, U., Badenhoop, K., Kaiser, S. M., Rittmaster, R. S., Shlossberg, A. H., Olivares, J. L., Loris, C., Ramos, F. J., Glorieux, F., Vikkula, M., Juppner, H., \& Strom, T. M. (2006a). DMP1 mutations in autosomal recessive hypophosphatemia implicate a bone matrix protein in the regulation of phosphate homeostasis. Nature Genetics, 38(1), 1248-1250.

Lorenz-Depiereux, B., Benet-Pages, A., Eckstein, G., Tenenbaum-Rakover, Y., Wagenstaller, J., Tiosano, D., Gershoni-Baruch, R., Albers, N., Lichtner, P., Schnabel, D., Hochberg, Z., \& Strom, T. M. (2006b). Hereditary hypophosphatemic rickets with hypercalciuria is caused by mutations in the sodiummphosphate cotransporter gene SLC34A3. The American Journal of Human Genetics, 78(2), 193-201.

Lorenz-Depiereux, B., Schnabel, D., Tiosano, D., Hausler, G., \& Strom, T. M. (2010). Loss-of-function ENPP1 mutations cause both generalized arterial calcification of infancy and autosomal-recessive hypophosphatemic rickets. The American Journal of Human Genetics, 86(2), 267-272.

Loymana, E., Tsyigina, A. N., \& Sarkisyana, A. A. (ed). (2010). Detskaya nefrologiya: Prakticheskoe rukovodstvo [Pediatric Nephrology: A Practical Guide]. Litterra, Moscow (in Russian).

Magen, D., Berger, L., Coady, M. J., Ilivitzki, A., Militianu, D., Tieder, M., Selig, S., Lapointe, J. Y., Zelikovic, I., \& Skorecki, K. (2010). A loss-of-function mutation in NaPi-IIa and renal Fanconi's syndrome. The New England Journal of Medicine, 362 (12), 1102-1109.

Natochin, Y. V. (2008). Klinicheskaya fiziologiya pochek u detey [Clinical kidney physiology in children]. Levsha, Sankt-Peterburg (in Russian).

Nijenhuis, T., Renkema, K. Y., Hoenderop, J. G., \& Bindels, R. J. (2006). Acidbase status determines the renal expression of $\mathrm{Ca}^{2+}$ and $\mathrm{Mg}^{2+}$ transport proteins. Journal of the American Society of Nephrology, 17(3), 617-626.

Novikov, P. V., Nedashevskiy, O. V., \& Semyachkina, A. N. (2004). Vtorichnyie osteopatii u detey s nasledstvennyimi boleznyami soedinitelnoy tkani i sposoby ih terapevticheskoy korrektsii [Secondary osteopathy in children with hereditary connective tissue diseases and methods of their therapeutic correction]. Yuzhno-Rossiyskiy Meditsinskiy Zhurnal, 2, 42-48 (in Russian).

Perwad, F., \& Portale, A. A. (2011). Vitamin D metabolism in the kidney: Regulation by phosphorus and fibroblast growth factor 23. Molecular and Cellular Endocrinology, 347(1-2), 17-24.

Pettifor, J. M. (2008). What's new in hypophosphataemic rickets? European Journal of Pediatrics, 167(5), 493-499.

Pishak, V. P., Ryznychuk, M. O., \& Xmara, T. V. (2015). Anomaliyi sechostatevoyi systemy: Vid teoriyi do praktyky [Anomalies of the urogenital system: From theory to practice]. BDMU, Chernivci (in Ukrainian).

Rodriguez Soriano, J. (2002). Renal tubular acidosis: The clinical entity. Journal of the American Society of Nephrology, 13(8), 2160-2170.

Saito, H., Kusano, K., Kinosaki, M., Ito, H., Hirata, M., Segawa, H., Miyamoto, K., \& Fukushima, N. (2003). Human fibroblast growth factor-23 mutants suppress $\mathrm{Na}^{+}$-dependent phosphate co-transport activity and 1 alpha,25-dihydroxyvitamin $D_{3}$ production. Journal of Biological Chemistry, 278(4), 2206-2211.

Savenkova, N. D., \& Leviashvili, Z. G. (2004). Diagnostika i lechenie nasledstvennogo sindroma de Toni-Debre-Fankoni [Diagnosis and treatment of the hereditary syndrome de Toni-Debreu-Fanconi]. Nefrologiya, 8(2), 57-65 (in Russian).

Shimada, T., Yamazaki, Y., Takahashi, M., Hasegawa, H., Urakawa, I., Oshima, T., Ono, K., Kakitani, M., Tomizuka, K., Fujita, T., Fukumoto, S., \& Yamashita, T. (2005). Vitamin D receptor-independent FGF23 actions in regulating phosphate and vitamin D metabolism. American Journal of Physiology. Renal Physiology, 289(5), F1088-1095.

Shimada, T., Hasegawa, H., Yamazaki, Y., Muto, T., Hino, R., Takeuchi, Y., Fujita, T., Nakahara, K., Fukumoto, S., \& Yamashita, T. (2004a). FGF-23 is a potent regulator of vitamin D metabolism and phosphate homeostasis. Journal of Bone and Mineral Research, 19(3), 429-435.

Shimada, T., Kakitani, M., Yamazaki, Y., Hasegawa, H., Takeuchi, Y., Fujita, T., Fukumoto, S., Tomizuka, K., \& Yamashita, T. (2004b). Targeted ablation of Fgf23 demonstrates an essential physiological role of FGF23 in phosphate and vitamin D metabolism. The Journal of Clinical Investigation, 113(4), 561-568.

Sitara, D., Razzaque, M. S., Hesse, M., Yoganathan, S., Taguchi, T., Erben, R. G., Jüppner, H., \& Lanske, B. (2004). Homozygous ablation of fibroblast growth factor-23 results in hyperphosphatemia and impaired skeletogenesis, and reverses hypophosphatemia in Phex-deficient mice. Matrix Biology, 23(7), 421-432.

Sun, Y., Wang, O., Xia, W., Jiang, Y., Li, M., Xing, X., Hu, Y., Liu, H., Meng, X., \& Zhou, X. (2012). FGF23 analysis of a Chinese family with autosomal dominant hypophosphatemic rickets. Journal of Bone and Mineral Metabolism, 30(1), 78-84.

Tasic, V., Kometi, P., Gucev, Z., Hoppe, B., Blau, N., \& Cheong, H. I. (2008). Atypical presentation of distal renal tubular acidosis in two siblings. Pediatric Nephrology, 23(7), 1177-1181.

Watanabe, T. (2017). Renal Fanconi syndrome in distal renal tubular acidosis. Pediatric Nephrology, 32(6), 1093.

White, K. E., Cabral, J. M., Davis, S. I., Fishbum, T., Evans, W. E., Ichikawa, S., Fields, J., Yu, X., Shaw, N. J., McLellan, N. J., McKeown, C., Fitzpatrick, D., Yu, K., Ornitz, D. M., \& Econs, M. J. (2005). Mutations that cause osteoglophonic dysplasia define novel roles for FGFR1 in bone elongation. The American Joumal of Human Genetics, 76(2), 361-367.

Wöhrle, S., Henninger, C., Bonny, O., Thuery, A., Beluch, N., Hynes, N. E., Guagnano, V., Sellers, W. R., Hofmann, F., Kneissel, M., \& Graus Porta, D. (2013). Pharmacological inhibition of fribroblast growth factor (FGF) receptor signaling ameliorates FGF23-mediated hypophosphatemic rickets. Journal of Bone and Mineral Metabolism, 28(4), 899-911.

Younes, N. A., Al-Trawneh, I. S., Albesoul, N. M., Hamdan, B. R., \& Sroujieh, A. S. (2003). Clinical spectrum of primary hyperparathyroidism. Saudi Medical Journal, 24(2), 179-183.

Zivičnjak, M., Schnabel, D., Billing, H., Staude, H., Filler, G., Querfeld, U., Schumacher, M., Pyper, A., Schröder, C., Brämswig, J., \& Haffner, D. (2011). Age-related stature and linear body segments in children with X-linked hypophosphatemic rickets. Pediatric Nephrology, 26(2), 223-231. 